\title{
Comparison of Polish and Portuguese hospital cost accounting methods
}

${\text { Amélia Silva }{ }^{*}, \text { Malgorzata Cyganska² }^{2}}$

ORIGINAL ARTICLE

\begin{abstract}
Dissemination of New Public Management ideology has motivated numerous studies about changes to management accounting practices in public healthcare organizations. However, few studies compare these practices on an international basis. The aim of the paper is to explore the differences and similarities in cost accounting practices within hospitals in different countries within the European Union. We follow a multiple comparative case-study approach. Qualitative data about the accounting practices of five hospitals, three from Poland and two from Portugal, are compared and discussed. Results show fairly similar models of cost accounting and an increasing need for accurately determined costs at hospitals in both countries. However, the data suggest some important differences in the way overhead is allocated. This study highlights the benefits of cross-country comparison practices. Moreover, this study points to the need for more qualitative cross-country research within management accounting topics.

Keywords: Cross-country research, Management accounting, Hospitals; Change, New Public Management, Case-study
\end{abstract}

\section{INTRODUCTION}

The health care system is defined by the World Health Organization as "all the activities whose primary purpose is to promote, restore or maintain health" (WHO, 2000, p.5). All over the world, many variations exist among healthcare systems. However, regardless of the specific configurations, hospitals are always among the key actors involved. Indeed, the scientific advances of medicine together with the growing development and sophistication of clinical technologies have moved hospitals to take their place at the center of the system. Actually, hospitals offer highly complex and differentiated care and are accountable for the greatest amount of health expenditures. Furthermore, costs of healthcare are rising significantly, particularly due to the aging of the population, thus increasing expectations for healthcare. In recent years, the global economic and financial crisis in Europe has heavily affected the public health sector, with the consequence of increasing pressure on cost control and budget constraints (Capanale, Cinquini, \& Tenucci, 2014). In addition to these cost-containment needs, there is an insatiable demand for free healthcare and growing high-quality standards claimed by citizens. Patients and their families think in terms of wellbeing, no matter how much it costs for the public system (Anderson \& Chalkidou, 2008).

Moreover, hospitals employ highly specialized professionals who are accustomed to a high degree of professional autonomy (Fitzgerald \& Dufour, 1998, Freidson, 2001, Evetts, 2013). The internal organization of Poland and Portuguese public hospitals corresponds essentially to what is called professional bureaucracy (Mintezberg, 2004). Two types of authority coexist in this model: the administrative authority that is clearly identified through the organizational structure and the professional authority that is structured essentially as a result of medical work. All of these factors together make reforms in healthcare organizations particularly difficult. In such a context, the need to secure the financial sustainability of the European Union's health

\footnotetext{
Manuscript received at August $4^{\text {th }} 2016$; Accepted at October $30^{\text {th }} 2016$

${ }^{1}$ Polytechnic Institute of Porto, CEOS, Centre for Organizational and Social Studies of Porto, Porto, Portugal

${ }^{2}$ University of Warmia and Mazury in Olsztyn, Poland

* Autor correspondente: R. Jaime Lopes Amorim, 4465-004, S. Mamede de Infesta, Portugal

E-mail: acfs@iscap.ipp.pt
} 
systems without undermining the values shared by the universal coverage, solidarity in financing, equity of access and the provision of highquality health care presents a big challenge (Thomson, Foubister, \& Mossialos, 2009). This challenge inspires an increasing need for accurately determining costs in hospitals. However, changes in accounting systems and governance in hospitals occur in a complex institutional environment among multiple stakeholders (Cardinaels \& Soderstrom, 2013). Indeed, the changing role and nature of accounting practices in healthcare are somehow erratic (Robson, 2008). These elements can only be understood in their social and organizational contexts (Laughlin, 1988) as well as in historical logic Gebreiter (2015). Thus, to understand changes in accounting thought and practice in healthcare, we must place it within the changes in medical knowledge and practice, the role of hospitals in medical treatment, the emergence of private insurance, changing forms of government regulation and changing social and political attitudes towards the cost and provision of health care (Preston, 1992).

There is evidence in the literature that the cost accounting system in healthcare is bounded by control structures and the funding system of the healthcare organization. The introduction of diagnosis-related group-based reimbursement is an example of this practice (Young, 1993). In the most developed countries, we had been assisting in a "movement away from cost-based reimbursement" (Orloff, Littell, Clune, Klingman, \& Preston, 1900) to "prospective payment" schemas in order to promote efficiency. Generally, changes in financing systems aim to achieve cost-effective healthcare provision, and so these changes are usually accompanied by changes in cost accounting in healthcare organizations. However, it is well recognized that the question of how to achieve cost-effective healthcare is too big to be individually answered; it poses to researchers "a challenge of truly daunting scale, scope and urgency" (Chapman, 2015, p.400). So, in order to contribute to this big question, we focused our attention on a specific dimension of the problem: do management accounting practices in hospitals differ across EU countries? The main objective of the study is to compare the accounting systems in Polish and Portuguese hospitals and report on the current practices of management accounting in hospitals. Since both countries have similar political contexts but differ in the arrangement of their healthcare system and public hospital organizational structure, it is expected that the development of accounting systems stage will also differ.

\section{BACKGROUND}

The most distinctive characteristics of any healthcare system are essentially categorized into four main topics: (i) the degree and manner of engaging the public authorities, (ii) the relative weight of each funding sources to cover healthcare expenditures, (iii) the reimbursement schema of healthcare organizations, and (iv) the ownership of the means of production. With regard to any of these topics, Portuguese and Polish healthcare systems have generally common political options, but there are important differences in the way each country operationalizes its political options. Moreover, they represent dissimilar historical, sociological and cultural backgrounds.

\section{Healthcare system in Poland}

Until the end of 1998, public health care services were mainly operating as budgetary units. The government was then both the principal insurer and the major provider of the services. On January 1, 1999, the institutions of universal health insurance commenced their activity by virtue of the Law of Universal Health Insurance. As a result, sixteen Regional Health Insurance (Sickness Funds) were established. They financed the healthcare institutions on the basis of the contracts. The hospital could negotiate the intensity of the services provided, but it had no influence regarding the reimbursement rate. That was because of the prospective system payment. In 2001, the new government declared centralization of the decentralized system by merging all Sickness Funds into the unified universal National Health Funds (NFZ). At present in Poland, the public funds covering expenditures on healthcare come 
from The Social Insurance Institution (ZUS), The Agricultural Social Insurance Fund (KRUS) and the state budget. The first institution collects contributions for social and health insurance and pensions from the employed or/and persons conducting non-agricultural business activity. KRUS collects contributions from farmers. The state budget covers contributions of some social groups entitled for health care services and a part of the health care services called highly specialized procedures local authorities' budgets - financing execution of tasks and competences of local governments. Poland boasts three main channels of public health care expenditures: The National Health Fund (NFZ), The Ministry of Health and local authorities. The specific tasks of the NFZ include carrying out open calling for proposals, conducting negotiations, concluding contracts for provision of health care services, monitoring their provision and settling the accounts. The instrument for the hospital reimbursement was the concept of Diagnosis Related Groups (DRG). It was initially applied to Medicare in the United States and progressively introduced into European countries (Nakagawa, Takemura, Yoshihara, \& Nakagawa, 2011). In Poland, the first attempts to implement the DRG system occurred during the application of the Sickness Funds in 1999-2003. The basis for the development of the Polish DRG system (JGP) was the British system of the Human Resource Groups (HRG). Its introduction was designed to reduce and optimize the hospital services, and the system was designed to be a tool for improving the productivity of hospitals. The NHF had to pay for the outcome (removal of the patient from the acute phase of illness requiring hospitalization), not for the provision of the hospital directory. Redefinition therefore underwent a product that the payer funded. According to the American model of DRG, patients were assigned to specific diagnostic groups. Each group had specific diagnostic characteristics, including patients with similar costs consumptions, and they required the use of the treatment of certain procedures in accordance with current medical standards.

\section{Healthcare system in Portugal}

Since the April Revolution in 1974, the Portuguese health system has undergone major changes. In general, it can be said that Portugal has followed the model of the English National Health Service (NHS). Since then, the social gains in terms of healthcare indicators, namely reduced infant mortality and increased life expectancy, are recognized by everyone. So, at the political level, there is a great agreement regarding the values of Portuguese NHS: universal, general and tendentiously free. However, from an economic point of view, the NHS represents a great financial effort for public budgets. Indeed, the economic and financial dimension of the NHS system generates serious sustainability problems. Currently, the public spending with healthcare is about $10 \%$ of GDP, and hospitals are responsible for more than $50 \%$ of it.

The first attempts to contradict this spending growth occurred in the 1990s. Since then, Portugal has experienced new governance models in public hospitals. These reforms are markedly influenced by the paradigm of New Public Management (NPM). By the end of 2002, approximately $50 \%$ of the public hospital network was transformed within the public enterprise. In contrast to previous reform programs, which had a gradual nature and rarely survived into political cycles, this reform create a "big bang" in the health sector (Guichard, 2004, p. 17), making the trajectory irreversible.

Despite the increasing decentralization, public hospitals continue to be directly controlled by governmental structures and continue to be funded almost entirely from the state budget, based on Diagnosis Related Groups (DRG).

The major change of this hospital enterprise reform is the split of purchasers and providers, the generalization of the private management models in public hospitals and the change of hospital financing system. The previous system, based on historical costs (inputs), was replaced by a financing system based on production (output). The new management models reinforce the importance of middle management, giving them greater responsibilities and 
requiring the development of leadership skills and technical knowledge, involving doctors with management and co-opting them to strategic decision areas. As a consequence, since 2002, the Portuguese government pressured over public hospital for reduction of costs and reinforcement of transparency and accountability did not stop growing.

The actual funding system of the hospital is based on a contract between the hospital and the Ministry of Health. After the Ministry of Health establishes the guidelines for the contract, the hospital board initiates the internal negotiation with the Director of Departments, and the Director of Departments negotiates with the Director of Services. This cascade negotiation process requires a sophisticated accounting system to support decision making and management control at all levels of the hospital. The implications of this new arrangement in the accounting system are described by Pettersen and Nyland (2011). This accounting logic (Broadbent \& Laughlin, 1995) was well visible in the later changes of the control system within Portuguese public hospitals. These changes emphasized the importance of monitoring hospital management based on the measures of outputs/inputs and outcomes.

Recently, with the crisis of Portuguese sovereign debt, the Portuguese government resorted to joint financial assistance from the European Commission, European Central Bank and International Monetary Fund, having committed itself to several measures to deal with the public debt. The healthcare sector emphasizes three main objectives:

- Improve efficiency and effectiveness in the health care system, inducing a more rational use of services and control of expenditures;

- Generate additional savings in the area of pharmaceuticals to reduce the public spending on pharmaceutical to 25.1 per cent of GDP by end 2012 and to about 1 per cent of GDP in 2013 (in line with EU average);

- Generate additional savings in hospital operating costs (Memorandum of
Understanding on Specific Economic Policy Conditionality, 2011).

\section{Comparison of healthcare expenditures and basic} healthcare indicators in Poland and Portugal.

For better understanding of the difference between the Polish and Portuguese healthcare systems, we compared health care expenditures (Table 1-3) and some basic healthcare indicators (Table 4-5) of both countries.

\section{Table 1}

Healthcare expenditure by financing agent in Poland and Portugal, 2012.

\begin{tabular}{lcc}
\hline \multicolumn{1}{c}{ (\% of current health expenditure) } & Poland & Portugal (1) \\
\hline $\begin{array}{l}\text { General government excluding social security } \\
\text { funds }\end{array}$ & 6.4 & 64.2 \\
$\begin{array}{l}\text { Social security funds } \\
\text { Private insurance enterprises (including } \\
\text { private social insurance) }\end{array}$ & 0.8 & 1.3 \\
Private household out-of-pocket expenditure & 24.3 & 4.9 \\
Non-profit institutions serving households & 1.4 & 0.1 \\
Corporations (other than health insurance) & 3.6 & 0.5 \\
\hline \multicolumn{2}{l}{ Source: Eurostat (http://ec.europa.eu/eurostat/statistics- } \\
explained/index.php/Healthcare_statistics)
\end{tabular}

In Portugal, the role of the government in financing healthcare is much more important than it is in Poland. As was mentioned previously, in Poland, the main role of financing health care expenditures is to play social security funds, called National Health Funds (NFZ). Social security funds cover almost $64 \%$ of total health care expenditures, while private household out-of-pocket expenditures represent $24,3 \%$ (Table 1). In Portugal, $64,2 \%$ of healthcare expenditures are financed directly from the Ministry of Health. The importance of the private household in financing healthcare is even higher than in Poland $(28,9 \%)$ (Table 1 ).

Table 2

Healthcare expenditure by function in Poland and Portugal.

\begin{tabular}{lcc}
\hline \multicolumn{1}{c}{ (\% of current health expenditure) } & $\begin{array}{c}\text { Poland } \\
(2012)\end{array}$ & $\begin{array}{c}\text { Portugal } \\
(2011)\end{array}$ \\
\hline Services of curative and rehabilitative care & 60.1 & 62.6 \\
Services of long-term nursing care & 7.0 & 1.7 \\
Ancillary services to healthcare & 5.1 & 8.8 \\
Medical goods dispensed to outpatients & 24.6 & 23.0 \\
Prevention and public health services & 2.0 & 2.1 \\
Health administration and health insurance & 1.2 & 1.8 \\
\hline
\end{tabular}

Source: Eurostat (http://ec.europa.eu/eurostat/statisticsexplained/index.php/Healthcare_statistics)

The percentage of healthcare expenditures on services of curative and rehabilitative care in Poland and Portugal is similar and stays near 
$60 \%$ of all healthcare expenditures. The main difference is the services of long-term nursing care. In Poland, the percentage of healthcare expenditures is $7 \%$ and relates to the nursing care performed at the homes of the patents who don't need hospitalization but still need medical care. It should be noted that limitations within the data compilation exercise make it difficult to separate the medical and social components of expenditure for long-term nursing care, leading to the inevitable impact on cross-country comparisons. In addition, the relatively low share reported for many EU Member States could result from the main burden of long-term nursing care residing with family members.

Table 3

Healthcare expenditure by provider in Poland and Portugal.

\begin{tabular}{lcc}
\hline \% of current health expenditure) & $\begin{array}{c}\text { Poland } \\
(2012)\end{array}$ & $\begin{array}{c}\text { Portugal } \\
(2011)\end{array}$ \\
\hline Hospitals & 34.8 & 38.7 \\
Nursing and residential care facilities & 1.8 & 1.6 \\
Ambulatory healthcare & 30.7 & 32.6 \\
Retail sale and medical goods & 24.0 & 22.9 \\
Administration of public health & 1.5 & 0.1 \\
programmes & & \\
General health administration and & 1.2 & 1.8 \\
insurance & 5.7 & 1.4 \\
$\begin{array}{l}\text { Other (rest of economy) } \\
\text { Rest of the world }\end{array}$ & 0.4 & 1.0
\end{tabular}

Source: Eurostat (http://ec.europa.eu/eurostat/statisticsexplained/index.php/Healthcare_statistics)

Upon analysing the healthcare expenditures by provider in Poland and Portugal, the difference within hospitals expenditures (almost $4 \%$ ) can be observed. Smaller differences can be observed within ambulatory health care, where the percentage of the expenditures in Poland and Portugal is $30,7 \%$ and $32,6 \%$, respectively.

Table 4

Healthcare indicators in Poland and Portugal, 2002 and 2011/12.

\begin{tabular}{|c|c|c|c|}
\hline (per 100000 inhabitants) & & Poland & Portugal \\
\hline Practising physicians & 2012 & 221 & 410 \\
\hline Hospital beds & 2011 & 655 & 338 \\
\hline $\begin{array}{l}\text { Hospital discharges of inpatients } \\
\text { (excluding healthy new born babies) }\end{array}$ & 2012 & 15630 & 15084 \\
\hline
\end{tabular}

Analysing some of the healthcare indicators, it can be noticed that in the year 2012, Poland and Portugal discharged almost the same number of patients (Table 3), but the resources used for them are quite different. This is confirmed by the physicians/hospital beds index, which in Portugal is 1,21 and in Poland is 0,34. In the Portuguese healthcare system, there are $20 \%$ more practising physicians than hospital beds, while in Poland, the number of beds is almost three times higher than the number of practicing physicians. The explanation of these differences is not the subject of the paper, but it confirms the differences in healthcare organizations in analysed countries.

Table 5

Hospital beds in Poland and Portugal, 2001, 2006 and 2011.

\begin{tabular}{llcc}
\hline (\% of current health expenditure) & & Poland & Portugal \\
\hline \multirow{3}{*}{ Curative care beds in hospitals } & 2001 & 506.7 & 299.1 \\
& 2006 & 465.2 & 282.3 \\
& 2011 & 429.3 & 280.8 \\
\hline \multirow{3}{*}{ Psychiatric care beds in hospitals } & 2001 & $:$ & 67.5 \\
& 2006 & 68.0 & 62.8 \\
& 2011 & 63.0 & 54.9
\end{tabular}

Source: Eurostat (http://ec.europa.eu/eurostat/statisticsexplained/index.php/Healthcare_statistics)

By analysing the proportion of curative care and psychiatric care beds in Poland and Portugal, it can be noticed that the proportion of psychiatric care beds in Portuguese hospitals is higher ( $16 \%$ of all hospital beds) than in Polish hospitals (10\%) (Table 5).

\section{METHOD}

Since there are too "many variations in the scope and shape of public sectors in the 196 countries of the world" (CIMA, 2011, p.6), researching under the assumption of a sole global health sector is incorrect. In healthcare, international comparisons are particularly difficult, namely because of the problems in data comparability and solution transferability (Schieber \& Poullier, 1989). Moreover, there is always the risk of underestimating the effects of social, cultural, medical, demographic, economic and political backgrounds. To minimize this risk, we opted for an exploratory case study approach, which allows us to understand better each reality under research. Our objective is to open up new research horizons for international comparisons research in cost accounting for 
hospitals. We do believe that international comparisons can facilitate the understanding of local reality and promote knowledge acquisition.

Rising healthcare costs are a global concern (Kaplan \& Porter, 2011), so hospitals face great pressure to improve their management systems. As already mentioned, both countries have mandatory hospital cost accounting systems regulation. However, many hospitals didn't fully cover this mandatory regulation (Cyganska, 2007). That's way we decided to analyse and compare the actual implemented solutions in hospital accounting systems. Our findings are based on an analysis of five hospitals. A standard questionnaire was used to collect empirical data. Four general characteristics of comprehensive cost systems have been chosen to compare the implemented costing methodologies in Polish and Portuguese hospitals. These characteristics are the detail of report data, identification of fixed and variable costs, accuracy of information and use of information in decision making (Thorly \& Johns, 1994).

Data collection relied on several sources, namely internal accounting reporting, financial statements, business plans documents, website information, official reports of governmental entities, legal documents and interviews with the Accounting Manager. The general characteristics of the sample hospitals are presented in Table 6 .

Table 6

Characteristics of studied hospitals.

\begin{tabular}{ccccc}
\hline Hospita & Country & No of departments & No of beds. & The founding body \\
\hline I & Poland & 15 & 292 & City hospital \\
B & Poland & 23 & 458 & Provincial hospital \\
C & Poland & 10 & 178 & County health care organization \\
D & Portugal & 62 & 1105 & Central and Teaching Hospital \\
E & Portugal & 13 & 331 & City hospital \\
\hline
\end{tabular}

The cost accounting in the public health care units has been practiced in Poland for several years, but it accelerated in the early '90s and was caused by the need of information resulting from changing health care organization system and the needs and possibilities of decision makers on different levels of management. The most important step in developing a healthcare cost accounting system was the regulation of the Minister of Health on cost accounting (The Regulation of the Minister of Health and Social Welfare took place on December 22, 1998 on the special rules of cost accounting in the public health care units). The methodology described in the regulation of the Minister of Health facilitated the calculation of the costs of health care units, cost centres, medical activities and cost drivers (per diem costs, medical procedure). The mandatory approach was a top-down methodology in which all general ledger costs were allocated to departments or specialties. The cost drivers were used to further disaggregate the costs to the services delivered. The sources of information for estimating the costs of treatment in Polish hospitals included generic per diem costs that represent the average cost of one hospitalization day irrespective of the patient condition, the costs of the drugs administered to the patient and the cost of the procedures performed to the patient. Although the regulations were mandatory to all the public hospitals, the range of their implementation was not homogeneous.

In the early 1990s, the single-entry bookkeeping model was predominant in the Portuguese public administration. Until then, the major objectives of public accounting entities were the budget monitoring and the control of the legality. In the late ' 80 s and early '90s, the reform of Financial Administration of the State reached a turning point in public accounting, specifically due to the changes in the law of the State Budget and the establishment of the Basis of Public Accounting. Since then, Portuguese public accounting has faced many challenges and experienced great improvements.

The public hospitals, however, faced different conditions. Indeed, Portuguese public hospitals 
applied the double-entry bookkeeping since the adoption of Official Chart of Accounts for Social Security in 1980. Later, this was replaced by the Official Chart of Accounts of Ministry of Health.

The Plan of Cost Accounting for public hospitals was approved in 1996. It introduced the normalization of cost accounting among hospitals. The proposed chart of accounts is structured according to the French method of homogeneous sections.

The aim of this system is essentially the budget control of clinical units, clinical departments and hospital as a unit. Once the cost information is aggregated by a central governmental body (ACSS), it facilitates the central control of hospitals' budget at a higher level. This is in addition to the basic cost accounting model, which is mandatory for all public hospitals. ACSS also controls other performance indicators, both management and clinical indicators. These indicators are used to benchmark public hospitals in order to promote economic rationality in the allocation of resources and stimulate the heads of clinical services to look for initiatives that provide efficiency gains without compromising the quality of services provided. This is the basic and mandatory model, but each hospital can develop a more sophisticated management accounting system.

\section{RESULTS AND DISCUSSION}

In Table 7 we presented the comparison of the main areas of cost accounting systems in healthcare according to the regulations in the analysed countries.

The Main Sections are generally coincident with the Clinical Services. The auxiliary sections are of two types: Auxiliary Sections of Clinical Support and Auxiliary Sections of General Support. Although classified as a main section, the Administrative Sections are treated as auxiliary sections once their costs are allocated to the remaining sections. An account is in place for unallocated costs. In order to ensure the subsequent consolidation of the accounts of all hospitals, the plan establishes the guidelines and the criteria for cost allocation. The allocation process ends at the Main Sections (cost centers).
There is no allocation of overhead to the patients.

Only the direct costs like drugs, clinical material and complementary diagnosis and therapeutic means are allocated to patients.

In both Portugal and Poland, there are certain regulations with which hospitals should comply. However, neither in Poland nor in Portugal have all hospitals implemented the accounting solutions. In Poland, the rate of hospitals that implemented the regulation is $79 \%$ (Baran, 2011) and in Portugal it's $100 \%$ (ACSS). For this reason, we decided to compare the actual implemented accounting system in 5 hospitals.

We proceeded with the standard questionnaire and conducted the interviews with the directors of the hospitals.

As can be seen in Table 8, not all analysed hospitals had implemented the accounting regulations. Hospital C hadn't calculated the costs neither by the procedures, nor by DRG or physicians. The costs here are assigned only to departments. In hospital C, the accuracy of data is very low, mainly because of the methods of cost accounting used. The top-down and gross costing methods are used here for the purpose of cost calculation. In the rest of the hospitals, the costs are calculated in a more precise way mainly because of the use of microcosting methodology. In hospitals $A$ and $B$, the microcosting methodology is used only in some areas. According to Polish regulations, in hospitals A and $\mathrm{B}$, the cost pools such as drugs and medical procedures are identified. In all hospitals for allocation of support cost centres, the simplest, most direct method is used. Through this approach, services provided mutually by support cost centres are ignored. Only in Portuguese hospitals are more sophisticated methods used.

For calculating costs of the procedures, several methods can be used. RCCs (ratios of costs-to-charges) divide the sum of the department's full costs for a year by the department's total charges for that year (Young, 2007). RVUs (relative-value units) use information from a national database to assign a weight to each procedure based on its complexity (Young, 2007). 


\section{$\mathbf{8 0}$ | A Silva, M Cyganska}

Table 7

Characteristics of areas of cost accounting systems in Polish and Portuguese hospitals

Areas of cost
accounting
systems

\begin{tabular}{ll}
\hline & Final cost centres: departments; Operating room; Laboratory; \\
& Support cost centres: Laundry; Kitchen; Emergency Room; \\
की & Pharmacy \\
की & Administration cost centre
\end{tabular}
Administration cost centr

\begin{tabular}{ll}
\hline In polish regulations there are three main costs classifications: \\
Cost classified by categories: Deprecation \\
External services, Materials and energy, Payroll, Employee \\
benefits, Other costs by categories \\
Costs classified by cost centers: Final cost centers; Support cost \\
centers and Administration cost centers \\
Direct vs. overhead costs classification
\end{tabular}

Intermediate products are healthcare services, like laboratory
a calculated by standard costing.
Final cost centres (clinical units): paediatric, otorhinolaryngology, ..., urgency.

Clinical support cost centres: diagnosis test, operating room, ..., anaesthesiology.

General support cost centres: maintenance of equipment and facilities, ..., hospitality.

Administrative centres: board administration, financial services, ..., human resources.

In Portuguese regulations, there are three main costs classifications:

Cost classified by categories: Deprecation

External services, Materials, Employees, Other operational costs; Financial cost

Costs classified by cost centers: Final cost centers; Support cost centers and Administration cost centers,

Unallocated costs

Direct vs. overhead costs classification.

At the first level, direct costs are allocated to each cost centre. Items of direct costs with higher weight are generally the personnel costs, pharmaceuticals, clinical material consumption, and depreciations, and these are allocated based on requests/real consumption. However, cost such as electricity, water, communications, depreciation of buildings and other constructions should be allocated based on the criteria set out in cost accounting plan.

At the second, the costs of administrative centres are distributed for auxiliary and final centres. But the services provided mutually between support cost centres are treated before the allocation of administrative costs to final and support centres. At the third level, the costs of the general support centres' support are distributed to the sections that beneficiated of their activities. For example, the cost of Food and Dietary Services are distributed to requesters depending on the number of weighted meals, the cost of clothing treatment section are distributed to requesters sections based on kg of cloths. In other cases, such as the Hygiene and Cleaning Services, Security and Car Services, the distribution is decided by each hospital.

At the fourth level, the costs of the clinical support centres are distributed to the final based on requested services. Intermediate products are provided by clinical support cost centres to the final cost centres, like laboratory tests, surgical procedures and imagology. Costs of intermediate products are calculated by real costs using the concept of weighted number. The weighting is defined according to the fixed price/fee establish by a legal diploma and charged by National Health Service to clients outside of NHS

Costs by patient or costs by DHG are not calculated. The system allocates to each patient only the drugs and the diagnosis tests provided outside the hospital.

The remained internal costs and the overhead accumulated in Final Cost Centres are not allocated to patients. The cost control is made at final centres, like it is in the hospital budget. 
Table 8

Costing systems characteristics in analysed hospitals.

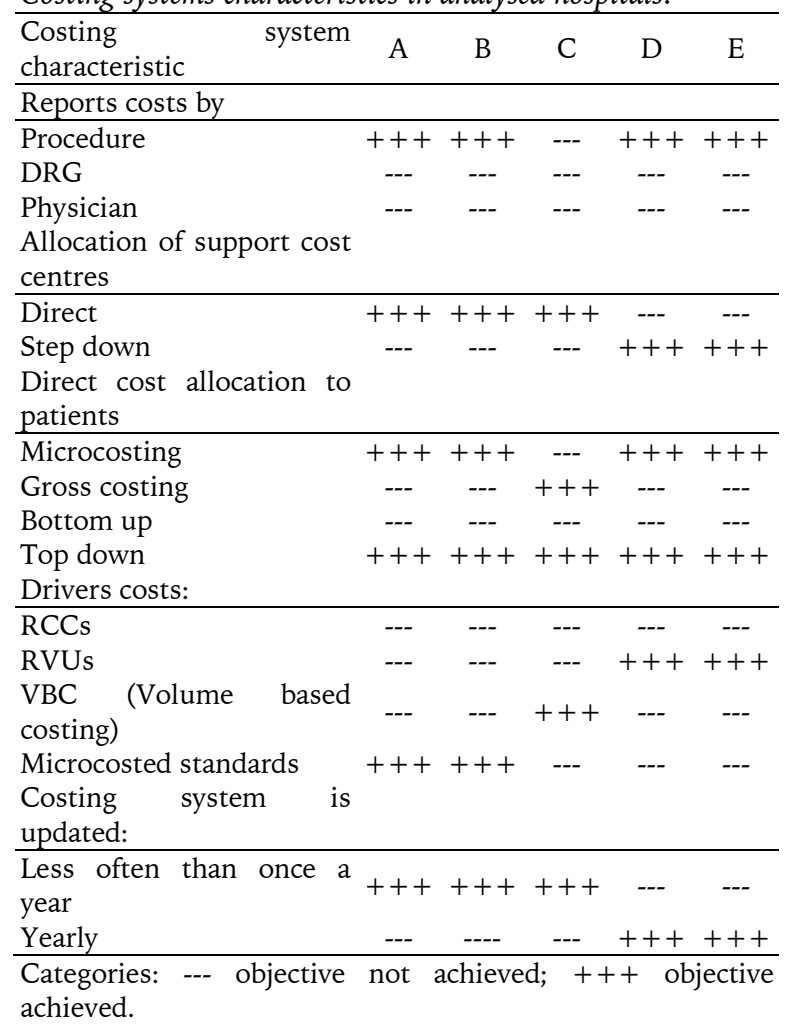

In two out of three polish hospitals the microcosted standards are used. The costing standards for all the medical procedures performed in the operation room were developed in the hospitals.

In Polish hospitals, the costing systems are not updated frequently. The main reason for this situation is the lack of educated staff, computer software and funds for implementing new solutions. In the Portuguese hospitals studied, the costing systems are updated systematically.

\section{CONCLUSION}

Our study shows a convergence tendency in cost accounting at the macro level (Guilding, Cravens \& Tayles, 2000), namely the concepts, ideas and methods applied. However, further studies are needed to understand the drives of such convergence.

At the micro level, there are still important options that undermine hospitals' benchmarking. Indeed, before we can proceed with cross-national benchmarking of costs (e.g. cost categories, cost of services, cost of procedures, cost of DRH), more detailed comparisons are needed, namely in the way overheads are allocated to cost centers and from cost centers to the final product (patient, DRH, procedure, surgery), and the range of services offered in hospital and outpatient settings. The main differences identified refer to the mutual services provided between cost centres, as Poland hospitals do not treat these centres as such, and the final product for cost calculation. The Portuguese assume final clinical centres to be the final product calculation, because this is the management level at which costs are managed and the hospital budget is controlled. Considering patient and DRG, Portuguese hospitals calculate only the revenue. These differences may indicate that cost accounting responds specially to needs related to financing and budget control instead of probability (Lapsley, 2001).

This paper provides additional evidence of the extent of international differences in healthcare costing systems. It differs from the previous work in the field. First, we followed a case study approach, which is very rare in international comparative studies. Our work thus differs from that of Guilding, Cravens, and Tayles (2000), who compare big data. It may shed light on the opportunities for knowledge transfer.

The widespread concern about increasing healthcare cost has prompted growing interest in studying the cost, cost-effectiveness and costbenefit of health interventions (Xu, Nardini \& Ruger, 2014). Indeed, the issue of whether cost accounting systems in healthcare organization improve healthcare efficiency is clearly an important one. However, it is too big to be studied in just one research project. Although international comparisons are difficult, they can be very useful for the creation of focused research questions.

\footnotetext{
Acknowledgments:

The authors thank participants at 3th Bemtur conference for their supportive comments on an early draft of this paper
} 


\section{Conflict of interest:}

Nothing to declare

\section{Funding:}

Nothing to declare

\section{REFERÊNCIAS}

Anderson, G., \& Chalkidou, K., (2008). Spending on medical care: more is better? Journal of the American Medical Association, 299(20), 24442445.

Baran, W. (2011). System rachunkowoś ci zarządczej w zakładach opieki zdrowotnej w Polsce. Zeszyty Teoretyczne Rachunkowości, (63), 5-24.

Campanale, C., Cinquini, L., \& Tenucci, A. (2014). Time-driven activity-based costing to improve transparency and decision making in healthcare: A case study. Qualitative Research in Accounting \& Management, $11(2), 165-186$.

Cyganska, M. (2007). Wykorzystanie rachunku kosztów w zarządzaniu wybranymi szpitalami. Zeszyty Naukowe Uniwersytetu Szczecińskiego. Prace Katedry Rachunkowości, (30), 31-39.

Eurostat. Your key to European statistics. Health care expenditure. Expenditure of selected health care functions by providers of health care [cited 23.03.2014]. Avaible from URL: http://ec.europa.eu/eurostat/web/health/health -care/data/database

Evetts, J. (2013). Professionalism: Value and ideology. Current Sociology, 61 (5-6), 778-796.

Fitzgerald, L., \& Dufour, Y. (1998). Clinical management as boundary management: A comparative analysis of Canadian and UK health-care institutions. Clinical Management, $12(4 / 5), 199-214$.

Freidson, E. (2001). Professionalism. The Third Logic. Oxford: Blackwell Publishers Ltd.

Gebreiter, F. (2015). Comparing the incomparable: Hospital costing and the art of medicine in postwar Britain. The British Accounting Review, 48(2), 257-268.

Guilding, C.,Cravens, K., \& Tayles, M. (2000). An international comparison of strategic management accounting practices. Management Accounting Research, 11 (1), 113-135.

Orloff, T. M., Littell, C. L., Clune, C., Klingman, D., \& Preston, B. (1990). Hospital cost accounting: Who's doing what and why. Health Care Management Review, 15(4), 73-78.
Lapsley, I. (2001). The Accounting-Clinical Interface-Implementing Budgets for Hospital Doctors. ABACUS, 37, 79-109.

Mintzberg, H. (2004). Managers not MBAs. San Francisco: Berrett-Koehler Publishers

Pettersen, I., \& Nyland, K. (2011). Reforms and accounting system changes: A study on the implementation of accrual accounting in Norwegian hospitals. Journal of Accounting \& Organizational Change, 7(3), 237 - 258

Pizzini, M. J. (2006). The relation between costsystem design, managers' evaluations of the relevance and usefulness of cost data, and financial performance: an empirical study of US hospitals. Accounting, Organizations and Society, $31(2), 179-210$.

Preston, A. M. (1992). The birth of clinical accounting: a study of the emergence and transformations of discourses on costs and practices of accounting in U.S. hospitals. Accounting, Organizations and Society, 17(1), 63100.

Laughlin, R. C. (1988). Accounting in its social context: An analysis of the accounting systems of the Church of England. Accounting, Auditing $\mathcal{E}$ Accountability Journal, 1(2), 19-42.

Kaplan, R. S., \& Witkowski, M. L. (2014). Better accounting transforms health care delivery. Accounting Horizons, 28(2), 365-383.

Robson, N. (2008) Costing, funding and budgetary control in UK hospitals: A historical reflection. Journal of Accounting \& Organizational Change, 4(3), 343-362.

Schieber, G. J., \& Poullier, J.P. (1989). Overview of international comparisons of health care expenditures. Health Care Financing Review 1, 17.

Thomson, S., Foubister, T., \& Mossialos, E. (2009). Financing health care in the European Union: challenges and policy responses. World Health Organization.

Xu, X, Nardini, G., \& Ruger J. (2014). Micro-costing studies in the health and medical literature: protocol for a systematic review. Systematic Reviews, 3(1), 1.

Young, D. W., \& Pearlman, L. K. (1993). Managing the stages of hospital cost accounting. Healthcare financial management, 47(4), 58-60

Young, D. (2007). The folly of using RCCs and RVUs for intermediate product costing. Healthcare Financial Management, 61(4), 100-108. 